\title{
$\mathrm{III}-\mathrm{V}$ 화합물 반도체 $\mathrm{InSb}$ 의 전기화학적 제조
}

\author{
이정오 · 이종욱 · 이관희 - 정원용 ${ }^{\dagger}$ - 이종엽* \\ 한국과학기술연구원 재료연구부 \\ *(주)우리정도, 충북 청주시 흥덕구 신봉동 153 \\ (2005년 6월 7일 접수 : 2005년 8월 3일 채택)
}

\section{Electrochemical Formation of III-V Compound Semiconductor InSb}

\author{
Jeong Oh Lee, Jong Wook Lee, Kwan Hyi Lee ${ }^{\dagger}$, Won Young Jeung ${ }^{\dagger \dagger}$, and Jong Yup Lee* \\ Materials Science and Technology Division, KIST, Seoul 130-650, Korea \\ ${ }^{*} R \& D$ Division, URi Fine Plating, Chung-buk 361-111, Korea
}

(Received June 7, 2005: Accepted August 3, 2005)

\begin{abstract}
초 톡
본 연구에서는 구연산 수용액 전해질을 제조하여 전기도금 방식에 의해 III-V족 화합물 반도체 InSb를 전기화학적으로 합성하였다. 본 연구에서 제조된 InSb는 기존문헌에서 보고된 바와 달리 EPMA 분석결과 In과 $\mathrm{Sb}$ 의 조성비가 52:48 로 화학양론을 정확하게 만족시키고 있고, XPS 분석결과 전해질내의 구연산의 농도가 $1.2 \mathrm{M}, \mathrm{pH}$ 가 4 일 때 $444.1 \mathrm{eV}$

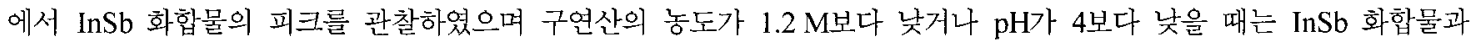
금속상태의 In이 흔재되어 있는 것을 확인하였다. 또한 $\mathrm{XRD}$ 를 통하여 $\operatorname{InSb}(111)$ 의 우선결정방위를 갖는다는 것을 확 인하였고, I-V 특성 곡선 측정을 통해 InSb가 고유한 반도체 특성을 보임을 확인하였다.
\end{abstract}

\begin{abstract}
We investigated the electrochemical formation of a stoichiometric III-V compound semiconductor of InSb from an aqueous citric solution. Under an? optimized electrochemical condition, not like other research results, the electrodeposited $\mathrm{InSb}$ are satisfied exactly with the stoichiometry. Furthermore it retains the inherent characteristics of III-V compound semiconductor, InSb without heat treatment. EPMA, XPS and XRD were employed for confirmation of its composition/stoichiometry, chemical state, and crystallographic orientation, respectively.
\end{abstract}

Keywords : InSb, III-V Compound Semiconductor, Electrodeposition.

\section{1. 서 론}

III-V족 화합물 반도체인 $\mathrm{InSb}$ 는 상온에서 전자의 이동도 (electron mobility)가 수만 $\mathrm{cm} / \mathrm{Vs}$ 로서 다른 반도체 물질에 비해 월등하 높으며 좁은 밴드 갭(band gap)과 유효질량이 적은 특 성을 지니고 있다. 좁은 밴드 갭 특성을 이용하여 $\mathrm{InSb}$ 는 적외 선 검출과 자기저항(Magneto Resistance) 센서 등으로 많이 적 용 되고 있으며, 열전소자 및 홀소자 등으로 다양하게 이용되고 있다. ${ }^{1-7)}$ 그리고 이들 분야에서 좋은 성능을 나타내기 위해서는 $\operatorname{lnSb}$ 의 단결정을 요구하지는 않으나 낮은 광학적 흡착과 정학 한 화학양론의 화합물이 요구된다.

화합물 반도체 $\mathrm{InSb}$ 박막을 제조하는 기존의 방법에는 열 증 착법(Thermal evaporation), 분자선 에피택시법(MBE: Molecular Beam Epitaxy), 화학기상증착법(CVD: Chemical Vapor

\footnotetext{
"Current address : Johns Hopkins University, kwanhyi@jhu.edu

${ }^{\dagger}$ E-mail; wyjeung@kist.re.kr
}

Deposition) 등이 있다. ${ }^{-7)}$ 이런 방법을 통해 InSb박막을 제조하 면 초고진공 분위기에서 수행을 하다보니 고가의 비용은 물론 이고, 구현할 수 있는 면적이 제한되며, 열에 의한 상변이가 일 어나기 쉽고, 소자 제조 공정에 적용하는데 어려움이 많이 따른 다. 전기도금 방식을 통한 화합물 반도체 $\mathrm{InSb}$ 의 전기화학적인 합성은 상온-상압 공정으로서 기존 공정의 문제점을 해결할 수 있으며 저가의 경쟁력 있는 공정을 개발할 수 있는 기반 기술 을 제공할 수 있다. 그러나 $\mathrm{InSb}$ 의 전기화학적인 합성은 몇몇 그룹에 의한 시도가 있었을 뿐 정확한 화학양론을 만족하는 $\mathrm{InSb}$ 의 제조에 대해 아직 보고된 바가 없다. Ortega 등은 $\mathrm{Ti}$ 기판을 작업전극으로 사용하여 정전압 전기도금을 실시하여 $\mathrm{InSb}$ 의 합성을 시도하였으나 화합물 반도체 InSb 뿐만 아니라 $\mathrm{In}$ 과 $\mathrm{Sb}$ 가 금속상으로 함께 전착된 상태를 얻었고 $\mathrm{InSb}$ 의 반도 체 톡성도 측정하지 못했다. ${ }^{8)}$ McChesney 등도 Ortega 등의 결과를 바탕으로 다른 조건을 제어하면서 정전압 도금에 의해 $\mathrm{InSb}$ 을 제조하였으나 역시 화합물 InSb 뿐만 아니라 금속 In, $\mathrm{Sb}$ 가 혼재된 형태의 박막이 제조되었고, $\mathrm{InSb}$ 의 광학적 특성을 
일부 측정하여 보고하였다. ${ }^{9)}$ 최근에 Fulop 등은 이전에 보고된 결과에 용액 중 $\mathrm{In}$ 이온과 $\mathrm{Sb}$ 이온의 농도비를 제어하고 최종 형성된 $\mathrm{InSb}$ 를 열처리하여 제조하였으나 여전히 화학양론을 정 확하게 만족시키는 $\mathrm{InSb}$ 를 합성하지는 못하였다. ${ }^{10)}$

따라서 본 연구에선 화학양론을 만족하는 III-V 화합물 반도 체 $\mathrm{InSb}$ 를 전기화학적으로 합성하기 위하여 전해질 중의 $\mathrm{pH}$ 와 구연산의 농도를 제어하였으며11) 이들 전기화학적 변수들의 영 향에 따른 화합물의 성분 분석과 결정구조 분석을 통해 전기화 학 변수와 화학양론 사이의 상관관계를 살펴보았다. 또한 기촌 그룹과는 달리 I-V 특성을 관찰하여 반도체 특성을 고찰하였다.

\section{2. 실험 방법}

화합물 반도체 $\mathrm{InSb}$ 를 제조하기 위하여 3-전극 전기화학 셀 을 구성하였다. 작업 전극에는 (100) 실리콘 웨이퍼 위에 $\mathrm{Au}$ 를 $2000 \AA$ 진공증착하여 사용하였으며, 용액 중에 노출된 면적은 $1 \mathrm{~cm}^{2}(1 \mathrm{~cm} \times 1 \mathrm{~cm})$ 로 일정하게 조절하였다. 또한 전기도금을 실시하기 전에 아세톤 용액 안에 1 시간 동안 초음파 세척을 실 시하였다. 보조전극으로는 고순도 $(99.9 \%)$ 흑연판재를 사용하였 으며, 기준전극으로는 $\mathrm{Ag} / \mathrm{AgCl}$ 을 사용하였다. 용액의 온도는 30 $\pm 1^{\circ} \mathrm{C}$ 로 일정하게 유지하였고, $\mathrm{pH}$ 와 구연산 이온의 농도를 조 절함으로써 $\mathrm{InSb}$ 박막의 성분비와 화학양론에 미치는 영항을 살 펴보았다. InSb 박막을 제조하기 위해 도금액은 $0.04 \mathrm{M}$ 의 염화 안티몬, $0.06 \mathrm{M}$ 의 염화인듑과 $0.6 \sim 1.2 \mathrm{M}$ 구연산을 기본으로 구 성하였고 이때 $\mathrm{pH}$ 는 2-4, 전류밀도는 $5 \mathrm{~mA} / \mathrm{cm}^{2}$ 범위에서 조절 하였다. 또한 제조된 InSb 박막은 EPMA (SX-50, CAMECA, $50 \mathrm{KeV}, 10 \mu \mathrm{A}$ )와 XPS (VG Microtech, England, ESCA $2000,15 \mathrm{kV}$ )를 통해 화학조성과 화학결합상태를 확인한 후 XRD (Bruker D8 advance, Germany, $25^{\circ} \mathrm{C}$ ) 분석을 실시하였 으며, $\mathrm{InSb}$ 박막의 반도체로서의 전기적 특성은 자제 제작한 챔 버와 홀더에 장착한 후 상온, 아르곤(Ar) 분위기에서 반도체 파 라미터 분석기(S/C parameter analyzer E5273A, Agilent, $\mathrm{USA}, \pm 100 \mathrm{~mA}$ )를 이용하여 I-V 곡선을 측정하였다.

\section{3. 결과 및 고찰}

$\mathrm{In}$ 과 $\mathrm{Sb}$ 는 열역학적으로 평형전위 차이가 크고, 속도론적으로 $\mathrm{Sb}$ 의 도금속도가 In보다 훨씬 빠르기 때문에 화학앙론을 만족 하는 $\mathrm{InSb}$ 화합물을 제조하기 위해서는 평형전위와 도금속도 차 이를 줄이기 위한 방법이 모색되어야 한다. 이에 본 연구에서는 구연산을 착화제로 사용하여 $\mathrm{In}$ 과 $\mathrm{Sb}$ 의 착화물을 생성시킴으로 써 이러한 문제점을 해결하고 $\mathrm{InSb}$ 화합물을 제조하고자 하였 다. 또한 $\mathrm{pH}$ 에 민감한 착화제의 특성 상 $\mathrm{pH}$ 와 착화제의 앙을 변화시키면서 $\mathrm{InSb}$ 화합물을 제조하여 그 특성을 고찰하였다. 먼저 $\mathrm{pH}$ 에 따라 어떻게 변하는가를 알아보기 위해 전해질내의 구연산의 농도를 고정시킨 후 $\mathrm{pH}$ 를 조절해가며 환원 분극곡선 을 살펴보았다. Fig. 1은 용액 중의 구연산의 농도를 $1.2 \mathrm{M}$ 로 고정시킨 후 $\mathrm{pH}$ 를 변화시킴에 따른 분극곡선 결과이다. Fig. 1 에서 알 수 있듯이 $\mathrm{pH}$ 가 2와 3일 때 측정된 Fig. 1(a)와 1(b) 의 결과에서는 본격적인 $\operatorname{lnSb}$ 의 환원반응이 시작되기 전에 -900 $\mathrm{mV}$ 근처에서 또 하나의 환원 피크를 관찰할 수 있으며, $\mathrm{pH}$ 가 낮을수록 그 반응이 많이 일어남을 알 수 있다. 환원 피크의 위 치로 보아 금속 상태의 In이 완전히 착화물로 형성되지 못하고 금속상태로 석출되는 반응으로 추정되었다. 이에 비해 Fig. 1(c)

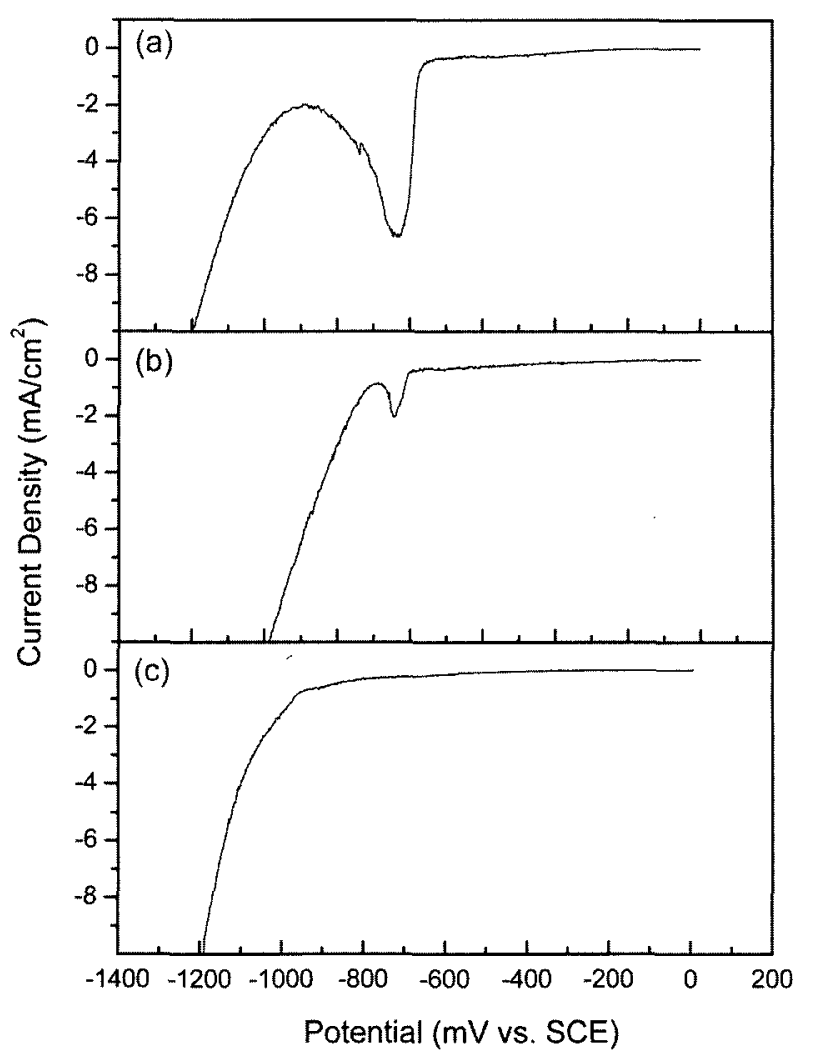

Fig. 1. Polarization curve of InSb as a function of $\mathbf{p H}($ fixed Citric acid $1.2 \mathrm{M}$ ) (a)pH 2, (b)pH 3, (c) pH 4.

처럼 $\mathrm{pH}$ 4일 때는 초기예 화합물을 형성하지 못한 금속상태의 $\mathrm{In}$ 의 석출 없이 $\mathrm{InSb}$ 화합물의 형성이 원활하게 이루어짐을 관 찰하였다. 착화물을 형성하지 못한 금속 상태의 $\mathrm{In}$ 의 석출이 $\mathrm{InSb}$ 의 화학양론을 방해하는 요인이라면 착화제 역할을 수행하 는 구연산의 양도 영향을 미치리라 예상할 수 있으며, 본 연구 에서는 전해질 내의 $\mathrm{pH}$ 를 4 로 고정시킨 후 구연산의 농도를 각 각 $0.6,0.9,1.2 \mathrm{M}$ 로 변화시켜며 분극곡선의 변화를 관찰하였 고 그 결과를 Fig. 2에 나타내었다. Fig. 1에서와 마찬가지로 착 화제로 사용된 구연산의 농도가 모자랄 때는 Fig. 2(a), (b)와 같이 금속 인듬의 석출이 분극곡선에서 나타나고 있으며, Fig. 2(c)의 $1.2 \mathrm{M}$ 일 때 $\mathrm{InSb}$ 착화합물의 형성이 용이함을 관찰하였 다. Fig. 1과 Fig. 2의 분극실험 결과로부터 용액 중의 구연산 의 농도가 $1.2 \mathrm{M}, \mathrm{pH}$ 가 4 일 때 화학양론을 만족시키는 $\mathrm{InSb}$ 화합물의 형성이 가장 원활하게 이루어지고, 용액 중의 구연산 의 농도가 $1.2 \mathrm{M}$ 이하이거나 $\mathrm{pH}$ 가 4 이하일 때는 $\mathrm{InSb}$ 화합 물에 금속상태의 In이 혼재된다는 것을 예상할 수 있으며, 원소 의 화학결합 상태를 알 수 있는 XPS 분석을 실시하여 그것을 검증하였다.

Fig. 3은 Fig. 1과 마찬가지로 용액 중의 구연산 농도를 1.2 $\mathrm{M}$ 로 고정시킨 후 $\mathrm{pH}$ 의 변화에 따라 분석한 High-resolution XP spectra이다. 443.6 과 $444.1 \mathrm{eV}$ 에서 두개의 피크를 확인할 수 있으며 이는 각각 In $3 \mathrm{~d}_{5 / 2}$ 와 InSb의 피크이다. $\mathrm{pH} 2$ 인 용 액 중에서 도금된 $\mathrm{InSb}$ 박막은 금속상태의 In $3 \mathrm{~d}_{5 / 2}(443.6 \mathrm{eV})$ 과 화합물 반도체인 $\operatorname{InSb}(444.1 \mathrm{eV})$ 가 혼재되어 있음을 보여주 고 있다. $\mathrm{pH}$ 가 3 인 용액 중에서 도금된 $\mathrm{InSb}$ 박막에서는 $\mathrm{In}$ $3 \mathrm{~d}_{5 / 2}$ 이 현저하게 줄어드는 것을 확인하였으나 In $3 \mathrm{~d}_{5 / 2}$ 과 $\mathrm{InSb}$ 
가 여전히 혼재되어 있음을 확인할 수 있었고, $\mathrm{pH}$ 가 4일 때 In $3 \mathrm{~d}_{5 / 2}$ 이 저의 나타나지 않으며 $444.1 \mathrm{eV}$ 에서 $\mathrm{InSb}$ 피크만을 관 찰할 수 있었다. 이러한 결과는 Fig. 1에서 InSb 화합물에 금속 $\mathrm{In}$ 이 혼재되어 있으며 $\mathrm{pH}$ 가 적을 수록 혼재되는 양이 많아진다 는 결과와 정확하게 일치한다.

Fig. 4는 Fig. 2에서와 같이 용액 중의 pH를 4로 고정시킨 후 구연산의 농도를 각각 $0.6,0.9,1.2 \mathrm{M}$ 로 변화시키면서 분석

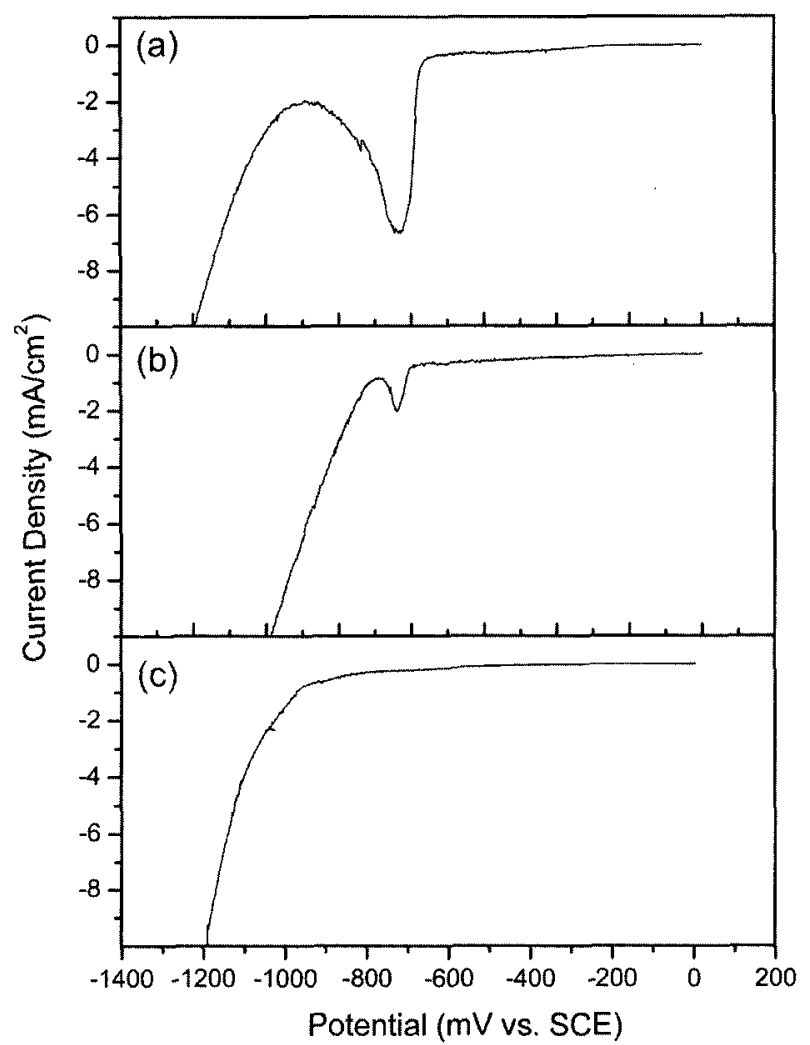

Fig. 2. Polarization curve of InSb as a function of Citric acid Molar concentration(fixed pH 4) (a)Citric acid $0.6 \mathrm{M}$, (b)Citric acid $0.9 \mathrm{M}$, (c)Citric acid 1.2 M.

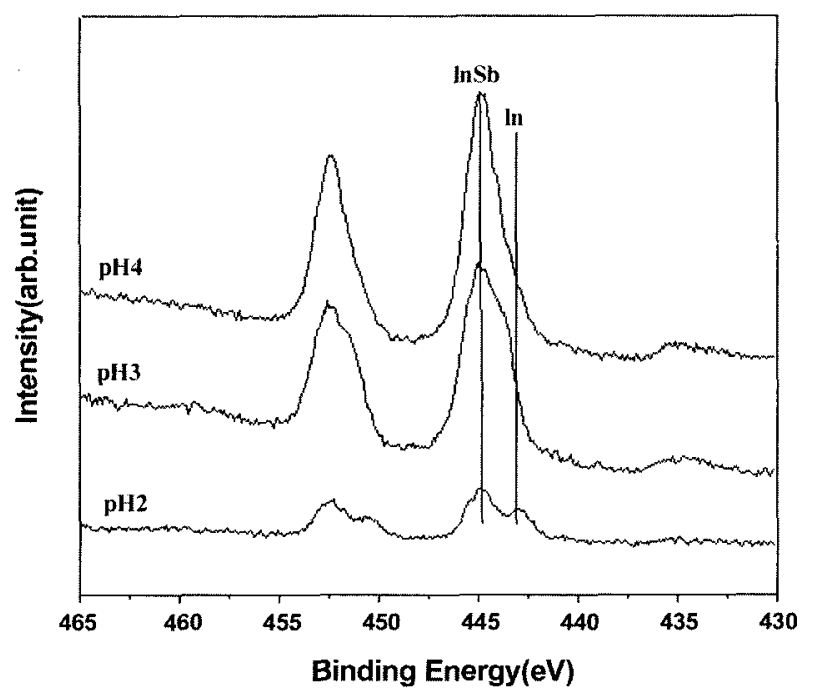

Fig. 3. High-resolution XP spectra of In 3d as a function of pH.
한 High-resolution XP spectra이다. Fig. 3에서와 마찬가지로 443.6 과 $444.1 \mathrm{eV}$ 에서 두개의 피크를 확인할 수 있었으며 이는 각각 $\operatorname{In~} 3 \mathrm{~d}_{5 / 2}$ 와 $\mathrm{InSb}$ 의 피크이다. 구연산의 농도가 $0.6 \mathrm{M}$ 인 용 액 중에서 도금된 InSb 박막은 Fig. 4(a)에서 In $3 \mathrm{~d}_{5 / 2}$ $(443.6 \mathrm{eV})$ 과 $\operatorname{InSb}(444.1 \mathrm{eV})$ 가 흔재되어 있음을 보여주고 있으 며, 구연산의 농도가 $0.9 \mathrm{M}$ 로 증가되면 $\mathrm{Fig}$. 4(b)와 같이 $\mathrm{InSb}$ 박막은 In $3 \mathrm{~d}_{5 / 2}$ 이 현저하게 줄어들되 여전히 In $3 \mathrm{~d}_{5 / 2}$ 와 $\operatorname{InSb}$ 가 혼재되있고, Fig. 4(c)와 같이 구연산의 농도가 $1.2 \mathrm{M}$ 이 되 어야 금속상태의 In $3 \mathrm{~d}_{5 / 2}$ 피크가 거의 나타나지 않으며 $444.1 \mathrm{eV}$ 에서 $\mathrm{InSb}$ 피크만을 관찰할 수 있다. 이는 역시 Fig. 2에서 살펴 본 분극곡선의 결과와 일치하고 있으며, 금속 In이 혼재되지 않고 화학양론을 만족하는 InSb 박막을 얻으려면 $\mathrm{pH}$ 4 에서 구연산의 농도가 $1.2 \mathrm{M}$ 이어야 함을 의미한다.

$\mathrm{InSb}$ 박막의 결정구조를 알아보기 위해 XRD 분석을 하였다. Fig. 5 는 구연산의 농도를 $1.2 \mathrm{M}$ 로 고정한 후 $\mathrm{pH}$ 가 각각 2,3 , 4 일 때 측정한 XRD 분석결과이다. $\mathrm{pH}$ 가 2, 3일 때는 Fig. 1의

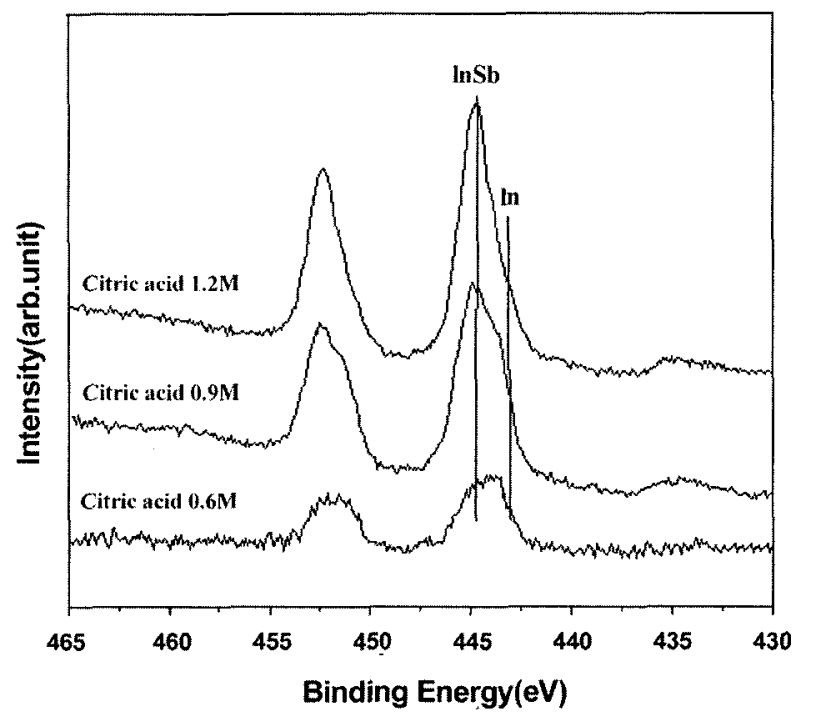

Fig. 4. High-resolution XP spectra of In 3d as a function of Citric acid Molar concentration.



Fig. 5. XRD spectrum of electrodeposited InSb. 


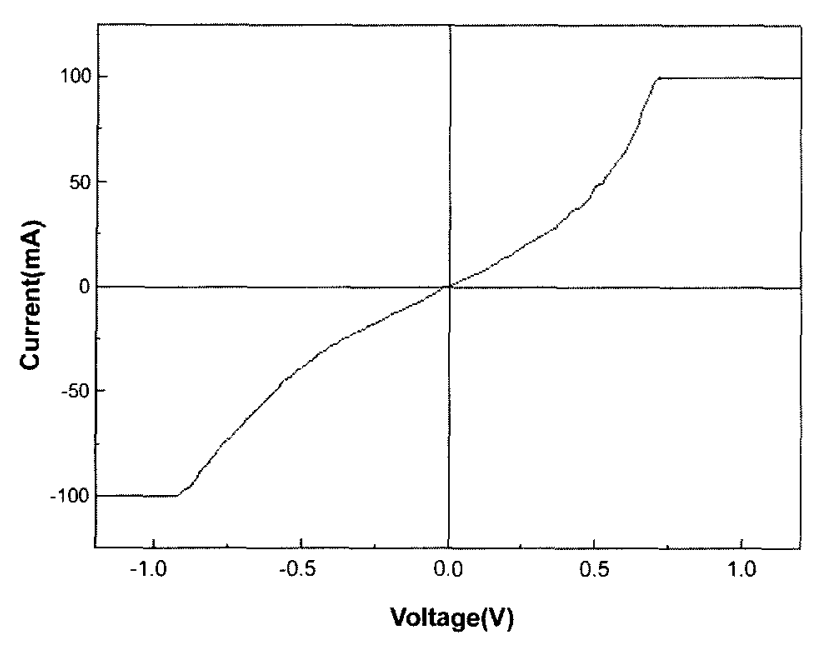

Fig. 6. I-V characteristic curve of the InSb.

분극곡선과 Fig. 3 의 XPS 결과와 동일하게 금속상태의 $\operatorname{In}$ 과 화 합물 $\mathrm{InSb}$ 가 혼재되어 있는 것을 확인하였고, $\mathrm{pH} 4$ 일 때는 Fig. 5(c)에서처럼 금속 $\operatorname{In}$ 의 석출 없이 정확하게 화학양론을 만 족하는 $\operatorname{lnSb}$ 를 얻을 수 있으며, 이때 InSb 박막은 [111] 방향 으로 우선결정방위를 갖는 다결정 박막임을 관찰하였다. 또한 EPMA를 통해서 조성분석을 실시하였을 때 In과 $\mathrm{Sb}$ 의 조성비 가 각각 52 대 48 로서 화학양론을 만족하고 있음을 확인하였다.

$\mathrm{InSb}$ 의 전기화학적 합성을 시도한 기존의 연구에서는 $\mathrm{InSb}$ 의 $\mathrm{I}-\mathrm{V}$ 특성을 관찰하지 못했다. 그러나 반도체의 전기적 특성과 그 종류(n형, $\mathrm{p}$ 형)까지 확인할 수 있는 $\mathrm{I}-\mathrm{V}$ 특성은 반도체의 가 장 중요한 물성 중의 하나이며 확인되어야 한다. Fig. 6에는 $\mathrm{InSb}$ 의 I-V 곡선을 나타내었다. 자체 제작한 챔버와 홀더를 이 용하여 상온에서 “4-probe 반도체 파라미터 분석기” 를 이용하 여 측정하였다. InSb 박막은 반도체 특성을 지니고 있어 유연 한 곡선 형태로 측정되나 $\mathrm{InSb}$ 가 밴드 갭이 적고, 상온에서 전 자이동도가 매우 큰 재료로서 금속에 유사하게 거동하는 반금 속(semi-metal) 형태의 반도체이기 때문에 Fig. 6에서와 같이 일 반적인 n형 반도체처럼 역방향으로 전류가 거의 0 에 가깝게 포 화되는 현상이나 역방향 전류항복 현상이 분명하게 관찰되고 있 지는 않는다.

\section{4. 결 론}

본 연구에서는 수용액 중의 구연산의 농도와 $\mathrm{pH}$ 를 조절하여 전기도금 방식에 의해 III-V족 화합물 반도체 InSb를 전기화학 적으로 합성하였다. 본 연구에서 제조된 $\mathrm{InSb}$ 는 기존문헌에서 보고 된 바와 달리 화학양론을 정확하게 만족시키고 있으며, 분 극곡선과 XPS, XRD를 통해 확인할 수 있었다. 또한 높은 전
자이동도와 좁은 밴드갭을 갖는 $\mathrm{InSb}$ 의 반금속(semi-metal)적인 특성으로 인해 금속과 기존의 $\mathrm{n}$-형 반도체와의 중간 특성에 해 당하는 $\mathrm{I}-\mathrm{V}$ 특성곡선에서 관찰하였다.

\section{감사의 글}

본 연구는 산업자원부 나노바이오-신기술융합(NT-IT)사업(나 노 정보소재 합성기술 개발)의 연구비 지원에 의해 수행되었으 며 이에 감사드립니다.

\section{참고문헌}

1. T. Miyazaki, M. Kunugi, Y. Kitamura, and S. Adachi, "Epitaxial growth of InSb films by r.f. magnetron sputtering", Thin Solid Films, 287, 51 (1996).

2. M. C. Debnath, T. Zhang, C. Roberts, L. F. Cohen, and R. A. Stradling, "High-mobility InSb films on GaAs (001) substrate grown by the two-step growth process" , J. Cryst. Growth, 267, 17 (2004).

3. T. Nakamura, M. Katagiri, Y. Aratono, I. Kanno, S. Hishiki, O. Sugiura, and Y. Murase, "Cryogenic neutron detector by InSb semiconductor detector with high-density helium-3 gas converter", Nucl. Instrum. Meth. A, 520, 76 (2004).

4. O. A. Mironov, M. Myronov, S. Durov, O. Drachenko, and J. Leotin, "Microminiature Hall probes based on $\mathrm{n}-\mathrm{InSb}(\mathrm{Sn}) / \mathrm{i}-\mathrm{GaAs}$ heterostructure for pulsed magnetic field applications", Physica B, 346347, 548 (2004).

5. A. Okamoto, H. Geka, I. Shibasaki, and K. Yoshida, “Transport properties of InSb and InAs thin films on GaAs substrates", $J$. Cryst. Growth, 278, 604 (2005).

6. T. Zhang, M. Debnath, S. K. Clowes, W. R. Branford, A. Bennett, C. Roberts, L. F. Cohen, and R. A. Stradling, "InSb epilayers on $\mathrm{GaAs}(100)$ for spintronic and magneto-resistive sensor applications", Physica E, 20, 216 (2004).

7. V. Senthilkumar, M. Thamilselvan, K. PremNazeer, S. K. Narayandass, D. Mangalaraj, B. Karunagaran, K. Kim, and J. Yi, "Characterization of p-type In-Sb thin films prepared by vacuum evaporation", Vacuum, in press.

8. J. Ortega and H. Herrero, "Preparation of $\operatorname{In} X(X=P, A s, S b)$ Thin Films by Electrochemical Methods", J. Electrochem. Soc., 136, 3388 (1989).

9. J. McChesney, J. Haigh, I. M. Dharmadasa, and D. J. Mowthorpe, "Electrochemical growth of GaSb and InSb for applications in infra-red detector and optical communication systems", Opt. Mater., 6, 63 (1996).

10. T. Fulop, C. Bekele, U. Landau, J. Angus, and K. Kash, "Electrodeposition of polycrystalline InSb from aqueous electrolytes", Thin Solid Films, 449, 1 (2004).

11. 이관희, 정원용, 이종엽, "전기도금에 의한 화학양론을 만족하는 III$\mathrm{V}$ 족 화합물 반도체 InSb의 제조방법” , 대한민국 발명특허, 20040083711 . 